\title{
As matrizes normativas da Nova Gestão Pública e - enfrentamento das desigualdades educacionais
}

\author{
Ana Maria Alves Saraiva \\ Universidade Federal de Minas Gerais (Brasil)
}

\section{Resumo}

Este artigo tem como objetivo discutir os conceitos de eficiência e de eficácia como matrizes valorativas que se apresentam para os sistemas educacionais. Compreende-se que tais matrizes emergem a partir da adoção de um novo modelo teórico na orientação da gestão estatal, denominado a Nova Gestão Pública (NGP). Com um desenho metodológico qualitativo, apoiado na análise bibliográfica e documental, o artigo tem como aportes teóricos principais as abordagens de Vigoda, Popkewitz e Van Zantem sobre as matrizes e racionalidades propostas pela NGP. Considera-se que esse modelo, ao introduzir a avaliação externa, a produção de indicadores e a construção de escalas universalizantes como ferramentas de gestão, altera a relação entre o Estado e a educação. Conclui-se que a incorporação da eficiência e da eficácia como matrizes normativas pela NGP em um contexto de persistentes desigualdades educacionais, estabelecendo metas universais de desempenho, não configura uma abordagem equitativa, o que apresenta limitações ao necessário enfrentamento dessas desigualdades.

Palavras-chave: Eficiência. Eficácia. Nova Gestão Pública. Desigualdades educacionais.

\section{The normative matrices of the New Public Management and the con- frontation of educational inequalities}

\begin{abstract}
This article aims to discuss the concepts of efficiency and effectiveness as evaluative matrices that present themselves for educational systems. It is understood that such matrices emerge from the adoption of a new theoretical model in the orientation of state management, called the New Public Management (NGP, in Portuguese abbreviation). With a qualitative methodological design, supported by bibliographic and documentary analysis, the article has as main theoretical inputs the approaches of Vigoda, Popkewitz and Van Zantem on the matrices and rationales proposed by the NGP. We consider that this model, introducing external evaluation, the production of indicators and the construction of universalizable scales as management tools, change the relationship between the State and the education. It is concluded that the incorporation of efficiency and effectiveness as normative matrices by NGP in a context of persistent educational inequalities, establishing universal performance goals, does not constitute an equitable approach, presenting limitations to the necessary confrontation of these inequalities.

Keywords: Efficiency. Effectiveness. New Public Management. Educational inequalities.
\end{abstract}


As matrizes normativas da Nova Gestão Pública e o enfrentamento das desigualdades educacionais

\section{Las matrices normativas de la Nueva Gestión Pública y la confronta- ción de las desigualdades educativas}

\section{Resumen}

Este artículo tiene como objetivo discutir los conceptos de eficiencia y efectividad como matrices evaluativas que se presentan para los sistemas educativos. Se entiende que tales matrices surgen de la adopción de un nuevo modelo teórico en la orientación de la gestión estatal, llamado Nueva Gestión Pública (NGP). Con un diseño metodológico cualitativo, respaldado por análisis bibliográfico y documental, el artículo tiene como principales contribuciones teóricas los enfoques de Vigoda, Popkewitz y Van Zantem sobre las matrices y los fundamentos propuestos por el NGP. Consideramos que ese modelo, al introducir la evaluación externa, la producción de indicadores y la construcción de escalas universales como herramientas de gestión, altera la relación entre el Estado y la educación. Se concluye que la incorporación de la eficiencia y la efectividad como matrices normativas por parte de la NGP en un contexto de persistentes desigualdades educativas, estableciendo objetivos de desempeño universales, no constituye un enfoque equitativo, lo que presenta limitaciones para la confrontación necesaria de estas desigualdades.

Palabras clave: Eficiencia. Eficacia. Nueva Gestión Pública. Desigualdades educativas.

\section{Introdução}

A gestão dos sistemas de educação no Brasil', cumprindo as orientações de uma agenda de reformas em sua estrutura e seus objetivos, passou por transformações significativas ao longo das últimas décadas do século XX. Em grande medida, essas mudanças apoiaram-se em uma pretensa inserção na denominada sociedade do conhecimento e da informação, estratégia central na tentativa de fazer-se competitivo em uma economia de larga escala, cada vez mais globalizada. $\bigcirc$ modelo de ingresso preconizava uma necessária redefinição do papel do Estado em suas mediações com a sociedade, sobretudo no âmbito das políticas sociais, dentre estas, a educação.

A agenda reformista apresentou-se para uma realidade interna, que se assentou em importantes desigualdades sociais e educacionais, como um projeto de modernização apoiado em um conjunto de valores, crenças, ideologias e metodologias que apontaram para novas formas de organizar o Estado e sua política educacional.

novo modelo de gestão, denominado a Nova Gestão Pública (NGP), é assim definido por Vigoda (2003, p. 1): "[...] um programa de reforma 
do setor público que aplica conhecimentos e instrumentos da gestão empresarial e de áreas afins e que tem por finalidade melhorar a eficiência, a eficácia e o desempenho geral dos serviços públicos nas burocracias modernas". A gênese da NGP é identificada pelo autor a partir de uma diferenciação conceitual entre os termos "administração" e "gestão" que começou a ser percebida no final da década de 1970. O termo gestão ganhou espaço a partir da crítica ao formato ampliado de tomada de decisão da administração pública. Seus defensores propuseram uma ação que minimizasse a atuação de instâncias participativas, consultivas e deliberativas da sociedade buscando um caminho mais estreitado que utilizasse como base decisória as impressões dos gestores, informações estatísticas e alguns saberes da psicologia organizacional.

Vigoda (2003) ainda afirma que somente a partir da mudança no setor público seria possível ampliar o alcance da gestão para abarcar, ao mesmo tempo, a iniciativa privada e as ações governamentais. Essa mudança dar-se-ia a partir de uma descentralização das ações, de uma redução do gasto social e da adoção de mecanismos centralizados de monitoramento e controle. Entretanto, tais ações não foram suficientes para caracterizar essa forma de gestão como uma "nova" gestão pública, pois tratava-se muito mais de uma transposição de modelo do que de uma inovação. Desse modo, na perspectiva do mesmo autor, o caráter de novo apresenta-se atrelado a um conjunto de ferramentas e técnicas que passaram a fazer parte da tomada de decisão política, como: a) o planejamento, a organização, o controle e a avaliação em detrimento da discussão sobre valores sociais; b) a crítica à democracia como empecilho à ação estatal; c) uma orientação instrumental favorecendo o uso dos critérios de economia e eficiência em vez de equidade; d) a tendência a considerar o gerenciamento como genérico, minimizando as diferenças entre o público e o privado; e) um afastamento da ciência política, filosofia ou sociologia aproximando-se muito mais das ideias administrativas práticas.

Embora esse processo de mudanças tenha se fortalecido ao longo do final dos anos de 1980 e início da década de 1990, o modelo gestor deriva de um período antecedente. No caso da educação, as agências internacionais começaram a tratar do tema na década anterior.

Assim, como veremos a seguir, a introdução do novo modelo de gestão se apoiou no ideário de substituição do "velho" Estado burocrático, resultado de uma construção que tem uma longa história, por um sistema mais 
As matrizes normativas da Nova Gestão Pública e o enfrentamento das desigualdades educacionais

"novo", quase profissional. A NGP ganha forças, a partir da segunda metade do século XX quando começou a ser disseminada uma nova noção de desenvolvimento, subjacente a um projeto de modernização da educação

\section{A Nova Gestão Pública}

A segunda metade da década de 1970 e a década de 1990 representam importantes marcos temporais na utilização da terminologia NGP para designar um novo formato de Estado². Em 1975, o termo surgiu com a obra de Michel Massenet: "La Nouvelle Gestion Publique: pour um Etat sans Burocratie "3 Posteriormente, o modelo denominado New Public Management ganhou espaço na administração pública, a princípio, nos Estados Unidos e, posteriormente, sobretudo nos anos de 1990, em outros países que o adotaram como resposta às críticas de ineficiência da ação estatal. Nesse período, mais precisamente em 1991, a obra "A public management for all seasons", de Crhistopher Hood, tratou de consolidar o termo (DASSO JUNIOR, 2014).

Na perspectiva da NGP, o objetivo da modernização do Estado seria alcançado a partir de alguns pontos considerados fundamentais e as agências internacionais tratariam de disseminar o modelo para outros contextos, sobretudo na educação, área estratégica de influência.

A atuação das agências internacionais, dentre estas, o BIRD (Banco Internacional para Reconstrução e Desenvolvimento), criado em 1944, passou a ter, a partir da década de 1970, a educação como um de seus focos principais, principalmente nos países latino-americanos, iniciando uma prática de condicionar os financiamentos e empréstimos ao avanço de indicadores. Para Fonseca (1998), nesse período, foram divulgados os primeiros relatórios setoriais para educação: Education, étude sectorielle em 1971; Documento de política sectorial em 1974; Education, politique sectorielle e Políticas del Sector Educacional e Educación e Desarrollo Humano, ambos em 1980, tendo - Banco como foco no período as possíveis consequências da expansão escolar, gerando um indesejável aumento do gasto público no setor, além da dificuldade de adaptar a expansão educacional, apontada como caminho, na Conferência Mundial de Educação para Todos (JONTIEM, 1990), à oferta de vagas em uma indústria que se modernizava rapidamente e ofertava, cada vez mais, menos empregos. 
Esse movimento de influência se intensificou nos anos 1990 com a publicação de documentos orientadores e relatórios técnicos, como uma de suas estratégias, baseados em dados estatísticos para justificar e nortear as tomadas de decisões no que dizia respeito à uma política educacional nos países mais pobres. Em nosso continente, a Organização das Nações Unidas para a Educação, a Ciência e a Cultura (UNESCO) por meio de sua representação regional a Comissão Econômica para a América Latina e o Caribe (CEPAL) tratou de disseminar as novas agendas para a educação a partir da publicação do documento de trabalho intitulado: Educación y Conocimiento: Eje de la Transformación Productiva con Equidad, em 1992, que fazia uma crítica aos objetivos vigentes da educação: "No passado, fez-se, com frequência, referência à cidadania como objetivo estratégico da educação, à equidade como sua perspectiva de orientação e à centralização como esquema de modelo institucional [...]". A CEPAL apontava o caminho necessário para a modernização, alinhando os objetivos da educação às novas demandas da competitividade global:

Embora essas matrizes tenham representado alguns avanços, elas se enfraquecem ao omitir-se em relação a outros componentes que compõem a atual proposta estratégica: a competitividade como objetivo, o desempenho como orientação da política e a descentralização como modelo de organização institucional (UNESCO/ CEPAL, 1992, p. 18).

Essa estratégia teve continuidade com o documento publicado pelo Banco Mundial em 1996 "Prioridades y Estrategias para la Educación", que trata da educação nos países periféricos. As mudanças na política educacional faziam-se necessárias para a garantia do desenvolvimento econômico e da empregabilidade na sociedade do conhecimento e da informação. Os avanços tecnológicos e as relações globais de trabalho determinariam os rumos da política educacional. Essas novas circunstâncias apontavam duas prioridades fundamentais para a educação: "[...] ela deve atender à crescente demanda das economias de trabalhadores adaptáveis, capazes de adquirir novos conhecimentos sem dificuldade e a produção de novos saberes" (BANCO MUNDIAL, 1996, p. 11.

Além disso, para monitorar o atendimento a essas novas demandas, o mesmo documento aponta que os sistemas de educação deveriam implementar 
As matrizes normativas da Nova Gestão Pública e o enfrentamento das desigualdades educacionais

mecanismos de avaliação de sua qualidade, com vistas a equiparar-se ou aproximar-se, futuramente, do desempenho dos países mais desenvolvidos: "[... a qualidade da educação nos países de baixa renda não é a mesma dos países da OCDE... [...] esses países podem adotar como indicador da qualidade de sua educação o valor agregado ou o desempenho medido em provas de conhecimento" (BANCO MUNDIAL, 1996, p. 50, grifo nosso).

No período, diversos países passaram a implementar sistemas nacionais de avaliação externa, ao mesmo tempo em que adotavam a produção de informações estatísticas da educação por meio da criação de bases de dados, como uma estratégia central dos órgãos responsáveis pela educação. No Brasil, o fortalecimento do Inep-como a mais importante autarquia de apoio ao Ministério da Educação, após um longo período de discreta ałuação, demonstra a centralidade que a produção de dados estatísticos assume. Isso está fortemente vinculado à própria história do Inep, contada aqui brevemente com o objetivo de demonstrar como a racionalidade proposta pela NGP demandou a criação de órgãos para gerir os sistemas de avaliação. $\bigcirc$ Inep foi criado em 1937 com o nome de Instituto Nacional de Pedagogia e destinava-se a realizar pesquisas sobre os problemas de ensino. Em 1938, com o Decreto-Lei 6 n. 580, suas atribuições foram mais bem definidas no sentido de organização documental e apoio técnico e pedagógico ao Ministério e aos estados.

Entretanto, a falta de pessoal e de suporte financeiro deixou a autarquia em segundo plano no que se refere ao processo político de tomada de decisões (MARIANI, 1982). A partir da década de 1990, com a criação do Sistema de Avaliação da Educação Básica (Saeb) e os preparativos para a sua primeira edição, o lnep é, então, promovido à condição de centralidade que ocupa hoje. Esse fortalecimento foi fundamental na extensão dessa estratégia de monitoramento e produção de dados educacionais para estados e municípios que igualmente criaram seus próprios órgãos e sistemas de avaliação e produção de informações estatísticas locais.

Ao adotar tais mecanismos em um contexto de desigualdades marcantes e persistentes, como é o caso brasileiro, percebe-se que uma retórica contraditória passou a figurar nos textos e documentos educacionais: desigualdades no acesso, problemas de fluxo, evasão escolar, baixo rendimento e dificuldades de aprendizagem passaram a dividir a cena com os emergentes "sistemas eficientes", "eficácia escolar", "avaliação do rendimento", "qualidade da educação" e "melhoria do desempenho". 
Essa agenda tem em sua base de implementação um novo conjunto de valores, crenças, teorias e ideologias que passaram a reorientar a gestão estatal a partir de paradigmas da iniciativa privada, e que se manifestaram no âmbito das políticas educacionais (OLIVEIRA, 2019). A sua efetivação, como marco orientador da política educacional a partir de uma promessa de futuro, demandaria, então, a substituição das matrizes e dos valores fundantes que, historicamente, orientaram a criação e a gestão dos sistemas educacionais (VAN ZANTEM, 2011 ).

No âmbito das políticas sociais, a NGP apresentou, como diretriz para a educação, a "modernização" a partir de um triplo movimento:

- a mudança das matrizes normativas dos sistemas educacionais;

- $\quad$ o estabelecimento de um modelo gerencial;

- A utilização de dados estatísticos e metodologias quantitativas como elementos de definição da política educacional.

Essas novas orientações surgiram em um momento de crítica à educação e suas matrizes fundantes. A ausência de um consenso em torno da igualdade de acesso, as investidas sobre a gratuidade e o avanço dos grupos religiosos sobre a educação forneceram um terreno fértil para emergência de uma nova racionalidade. É dessa forma, baseadas em um discurso de perícia científica, que a eficácia e a eficiência emergiram como um projeto de modernização da educação.

\section{A eficiência e a eficácia como matrizes normativas}

A escola republicana e os sistemas educacionais que se organizaram ao seu redor trataram de estabelecer suas finalidades e valores a partir de matrizes universalistas. A laicidade, a gratuidade e a igualdade no acesso são exemplos desses ideais fundantes e orientadores, presentes em maior ou menor medida, ao longo da estruturação dos sistemas de educação na Europa, nos Estados Unidos e no Brasil. Essas matrizes valorativas representam algo além da dimensão conceitual e filosófica. São construtos que tratam de valores que são constituintes do Estado republicano, contribuindo, ainda, para a consolidação da unidade nacional a partir da garantia da igualdade quaisquer que sejam as convicções pessoais (VAN ZANTEN, 2011 ) 
As matrizes normativas da Nova Gestão Pública e o enfrentamento das desigualdades educacionais

Também, na perspectiva de Déloy (1994, p. 53): "Essas dimensões entrelaçam uma dimensão cognitiva: o papel atribuído ao conhecimento na emancipação social, com uma dimensão normativa, ou seja, o desenvolvimento de uma ética coletiva concorrente das éticas religiosas."

No caso brasileiro, Cunha (2016) aponta para um movimento contínuo de avanços e recuos da laicidade como princípio educacional, considerando a dicotomia presente entre secularização e laicidade no Estado brasileiro. A dimensão política subjacente a esses valores passou a ser de extrema importância na legitimação da República como lócus da cidadania em construção:

Decorre daí que, no Estado laico, a moral coletiva, particularmente a que é sancionada pelas leis, deixa de ser tutelada pela religião, passando a ser definida estritamente no campo político. Isso quer dizer que as leis, inclusive as que têm implicações éticas ou morais, são elaboradas com a participação de todos os cidadãos, sejam eles religiosos ou não (CUNHA, 2016, p. 4).

Da mesma forma, o progressivo avanço da obrigatoriedade escolar vinculou-se a uma possível emancipação cidadã, seja pelo apartamento dos 8 coletivos em torno de um ideal de pertencimento ou a um pertencimento de fato pelo acesso aos direitos sociais, dentre eles, a educação. A igualdade e a laicidade, juntamente com a noção de progresso, estabeleceram a crença na educação como um valor absoluto, inerente à transformação social. Essas matrizes valorativas, entretanto, foram se esmaecendo ao longo da segunda metade do século XX.

A igualdade de acesso confrontou-se com a crítica ao ideal de igualdade de oportunidades e o fracasso dos alunos oriundos dos meios mais vulneráveis, gerando fortes críticas ao modelo de "democratização quantitativa do acesso". O termo criado por Antoine Prost (1986) considera que o processo de democratização é apenas quantitativo quando permite o acesso a um bem, nesse caso a educação, sem suprimir as desigualdades maiores, provocando apenas um deslocamento do "lugar" das desigualdades que passam a ser escolares além de sociais. Posteriormente, as críticas foram direcionadas, da mesma forma, às políticas de caráter compensatório postas em prática nas escolas localizadas em territórios de alta vulnerabilidade social.

Desse modo, ao ampliar o acesso sem que os "novos" alunos tivessem as mesmas oportunidades de permanência e prolongamento dos anos 
de estudos, a desigualdade não foi eliminada, mas apenas deslocada para o ambiente escolar, tornando, assim, a democratização apenas quantitativa. Destarte, ocorreu também com a laicidade que passou por um processo de enfraquecimento como matriz valorativa fundante dos sistemas educacionais. A influência religiosa deslocou-se, cada vez mais, para o debate político e normativo referente à política educacional, para os embates sobre o currículo ou ainda como definidora de uma conduta ética dos docentes, perdendo forças como um valor fundamental dos sistemas de educação.

Da mesma forma, a gratuidade sofreu pressão de setores que defendiam uma maior participação dos entes privados na educação, por meio da produção e venda de materiais didáticos aos sistemas públicos, da oferta privada de formação continuada e até mesmo de um modelo híbrido de privatização dos sistemas educativos como as PPPs (Parceria Público Privado), representando diferentes faces de um capitalismo cognitivo (MOULIERBOUTANG, 2007).

O esmaecimento dessas matrizes constituiu um terreno fértil, em certa medida, para a ascensão das novas matrizes propostas pela NGP. Termos como eficiência, eficácia, rendimento e desempenho surgiram em um espaço anteriormente dedicado às temáticas da laicidade, da gratuidade e da igualdade. Assim, a falta de um consenso em torno da igualdade meritocrática, o enfraquecimento da laicidade e o avanço do mercado sobre a educação abriram caminho para a eficiência e a eficácia, legitimadas por um regime de verdade neoliberal, que defendia a predominância desses valores em detrimento dos anteriores, mais abstratos e menos efetivos na competitividade econômica mundial (BALL, 1994).

Nesse sentido, a eficiência e eficácia se apresentaram como matrizes legitimadoras de um discurso valorativo da política educacional. Foram conceitos que advieram de naturezas distintas e que se justificavam como valores fundantes da Nova Gestão Pública para a educação. Para Madaus, Airasian e Kellaghan (1980), há uma diferença importante entre eficiência e eficácia. A eficiência é um conceito econômico, uma medida do desempenho do sistema a partir do custo dos seus resultados, representa um cálculo econômico para estabelecer se os produtos correspondem aos investimentos realizados. Por outro lado, a eficácia é um conceito escolar, que diz respeito à capacidade das escolas de produzirem efetivamente os resultados esperados. A eficácia 
As matrizes normativas da Nova Gestão Pública e o enfrentamento das desigualdades educacionais

passou a ser mensurada a partir de duas metodologias, o efeito-escola e a escola eficaz.

Na análise de Derovet (2009), a escolha por uma medida tem o objetivo de abertura da escola para a consolidação das avaliações externas em larga escala e para um futuro processo de responsabilização. Uma medida da escola, a partir de avalições externas com a divulgação de resultados sem a devida mediação que leve em conta as diferentes realidades, transfere para a escola a responsabilidade pelo avanço de seu desempenho e do próprio sistema, pois nessa perspectiva o avanço do sistema depende do avanço de cada escola.

A entrada em cena dessas novas matrizes, ao contrário de suas antecessoras, não se deu de forma imediata, demandou um percurso para sua validação como matrizes universais, pois tratavam de valores que precisavam ser legitimados como matrizes normativas dos sistemas e orientadoras da política educacional.

Esse processo de legitimação se assentou principalmente na forma de um ideal universalizante, concretizado pelos avanços e usos excessivos da estatística na educação, um fenômeno que se materializou no estabelecimento de rankings nacionais e internacionais, produzindo indicadores que moldaram uma nova compreensão do que seja a educação. Os números, que parecem neutros e precisos, foram reconstruídos em termos de sua representação social para que o processo de "tradução" fosse possível. Na lógica da educação pelos números, os dados estatísticos produzidos nacional e internacionalmente não são apenas ferramentas para análises, mas também altamente performativos, pois enquadram nossos pensamentos e concepções acerca da tomada de decisões na política educacional (LINDBLAD; PETTERSON; POPKEWITZ, 2018). Esses movimentos foram essenciais para o Estado gerencial, a "forma" assumida pelo Estado na área da educação na NGP.

\section{O estabelecimento de um modelo gerencial}

A NGP promove um deslocamento um tanto brusco e conflitante do Estado-providência para um Estado "menor", gestor, gerencialista, adotando características oriundas da iniciativa privada. Esse modelo na educação é baseado em uma gestão por resultados, na criação e ampliação dos mecanismos 
de avaliação externa e na produção de indicadores educacionais que aproximam o conceito de qualidade da noção de desempenho.

Esse movimento permite conduzir a gestão da educação de forma mais distanciada, apoiando-se na eficiência comprovada pela interface com a evidência estatística, valorizando as pesquisas quantitativas produtoras de indicadores que permitem classificar e avaliar as políticas e os programas públicos pela sua eficiência, descartando aqueles que não a comprovem (DEROUET, 2009; LESSARD, 2011 1.

Na análise de Mintrop (2019), o estabelecimento de um Estado gerencial foi precedido por um modelo neoliberal de (des)regulamentação do trabalho que enfraqueceu os sistemas de representação, tornando a educação um espaço de pouca resistência para a adoção das medidas de mecanismos de controle externo e de criação de um aparato centralizado de pilotagem a distância.

Nesse contexto, os dados estatísticos alimentam não somente a tomada de decisão local, mas também o discurso das políticas itinerantes, elaboradas de forma que o subsequente processo de tradução transnacional seja possível. A tradução ocorre quando os parâmetros comparáveis de excelência produzidos pelas agências internacionais se transformam em políticas, práticas e referências em diferentes contextos, estabelecendo um regime de comparação perpétua, no qual os funcionários das agências (no caso a OCDE / PISA) agem não apenas como "agitadores" ou "instigadores", mas também como "mediadores" e "construtores de redes". Eles devem criar condições favoráveis para a tradução e, ao mesmo tempo, estar atentos às diferentes traduções e apropriações dos resultados de suas pesquisas para alimentar as necessárias reelaborações na relação entre o global e o local (NÓVOA; CARVALHO; YANES, 2014).

As políticas itinerantes têm na estatística comparada uma aliada fundamental para o estabelecimento de categorias de equivalência que permitam a comparação entre os diferentes países. Para Lindblad, Petterson e Popkewitz (2018), essa comparabilidade se configura como um dos mais importantes instrumentos de ação política. Nesse cenário apontado pelos autores, os números deixam de ser somente ferramentas de análises, mas também se tornam altamente performativos, construindo representações sobre como são e como 
deverão ser os alunos, professores e até mesmo as famílias na excelência estatística educacional.

Assim, são igualmente construídas as boas práticas preconizando o desenvolvimento da qualidade de um sistema educacional a partir da adoção de políticas de outros contextos que alcançaram o nível estabelecido pelas avaliações internacionais. Parte-se para um modelo de educação baseada na prova (SAUSSEZ; LESSARD, 2009). Para os autores, percebe-se também, ao longo das últimas décadas do século XX, um movimento de "simplificação" da pesquisa científica que tem a educação como campo de investigação e estudos, fenômeno que vai de encontro com o que é preconizado pela OCDE, como veremos a seguir no terceiro e último movimento de substituição das matrizes normativas da educação.

\section{A utilização de dados estatísticos e metodologias quantitativas para tomada de decisão na política educacional}

Embora o uso da evidência estatística como ferramenta para a tomada 12 de decisão seja bem atual na política educacional, o tema não é recente. Ao final da Segunda Guerra Mundial, os indicadores sociais tiveram um desenvolvimento importante, sobretudo nos Estados Unidos. No decorrer dos anos de 1960, a análise crítica de mitos e crenças sociais assumiu um papel importante e as informações produzidas no âmbito das ciências sociais tornaram-se cada vez mais centrais para a formulação e avaliação das políticas sociais (MOSTELLER; MOYNIHAN, 2008).

Posteriormente, em um movimento que Burns e Schuller (2007) denominam de (re)surgimento da evidência, a OCDE publicou, em 1995, o documento intitulado: Pesquisa e desenvolvimento educacional: tendências, questões e desafios, que apresentava algumas razões para esse fenômeno, destacando, dentre elas, a crença na educação como fator de inovação e crescimento, o aumento da preocupação com a prestação de contas das despesas com educação e também a queda da qualidade e da eficácia da pesquisa em educação.

Nos anos seguintes, o tema continuou a ser abordado em mais duas publicações: New Challenges for Educational Research, em 2003, e Innovation in the Knowledge Economy: Implications for Education and Learning, em 2004, 
ambas tecendo críticas à pesquisa em educação e ressaltando a necessidade de mudanças, advogando em prol de uma pesquisa que fornecesse caminhos únicos e não difusos.

Em 2007, a OCDE lançou a publicação orientadora Evidence in Education: Linking Research and Policy reforçando a ideia de que uma educação baseada na prova é uma necessidade. O documento preconizava um necessário rompimento com modelos que se baseavam no reconhecimento do caráter complexo da educação e que sugeriam uma diversidade de caminhos para a aprendizagem: "[...] a pesquisa disponível é contraditória e não sugere um único curso de ação. É crucial que as decisões sobre políticas educacionais sejam tomadas com base nas melhores evidências possíveis" (p. 3).

Um movimento que defendeu uma redução da complexidade da pesquisa nas ciências humanas em geral e, mais especificamente, no campo da educação ganhou forças e estabeleceu novas relações entre a política e a pesquisa empírica, sobretudo aquela de natureza quantitativa. Esta direcionou, em certa medida, as ações dos órgãos governamentais responsáveis pela educação nacional, e mesmo os departamentos de pesquisa das universidades (VAN ZANTEN, 20111 , para um tipo de pesquisa que fornecia evidências quantitativas, que não considerava de forma mais abrangente a diversidade presente na educação, nos seus processos e nas suas práticas. Observa-se ainda o uso indiscriminado de indicadores que alimentaram um processo de homogeneização de redes, escolas e alunos, resultando em um fenômeno que Lindblad, Petterson e Popkewitz (2018) denominam de "Educação pelos números" como o caminho para que se alcançasse a excelência numérica, utilizando-se do desenvolvimento da estatística e do surgimento de softwares de medição de desempenho estudantil para estabelecer parâmetros universais.

\section{O discurso da excelência e o enfrentamento das desigualdades educacionais}

A difusão de um discurso de diferenciação e classificação dos países em uma escala de valores quantitativos, como ocorre atualmente no PISA, demanda a construção prévia de indicadores que modelam diferentes realidades de forma a torná-las estatisticamente comparáveis. Essas escalas são essenciais para prover os rankings de excelência e fracasso na educação. 
As matrizes normativas da Nova Gestão Pública e o enfrentamento das desigualdades educacionais

Entretanto, não são de fácil elaboração, demandam a existência de parâmetros universais, de um processo prévio de homogeneização de contextos e realidades sociais distintas para sua efetividade. A prática não é uma invenção da sociedade do conhecimento e tampouco exclusiva do campo educacional. Ela remonta um período de restabelecimento das relações de dominação econômica e nasce pari passu com as agências internacionais de influência.

A utilização mais contundente da estatística na tomada de decisões tem sua gênese na economia e remonta ao período pós-Segunda Guerra Mundial, quando foram criadas o que Marini (1994) denomina de "agências de difusão de teorias", sob a cobertura da ONU, nas quais se destacaram as comissões econômicas para a Europa (UNECE) e também para a Ásia e Extremo Oriente (ECAFE), em 1947. No ano seguinte, foi criada a Comissão Econômica para a América Latina e Caribe (CEPAL). Esta última, encarregada da difusão das teorias do desenvolvimento, sobretudo da Teoria do Capital Humano, em um contexto de inquietude diante das desigualdades percebidas com a recente descolonização (OLIVEIRA, 2000).

Nos anos subsequentes, a CEPAL tratou de elaborar e difundir a sua 14 teoria do desenvolvimento, apoiada no avanço das ciências sociais e em uma robusta produção científica com a região como objeto de reflexão. Essa teoria tomou os países centrais como referência de desenvolvimento e tratava de explicar e justificar as disparidades entre o centro e a periferia por meio de diferenças estruturais, populacionais, entre outras. Ao mesmo tempo, construía e difundia conceitos e estratégias que permitiriam aos países subdesenvolvidos alçarem, em algum momento, à condição de desenvolvidos (PREBISCH; FURTADO; PINTO, 1994).

A classificação dos países em desenvolvidos e subdesenvolvidos se baseava em uma série de indicadores quantitativos (renda per capita, índices de alfabetização e escolaridade, taxas de natalidade e expectativa de vida etc.) que foram incapazes de retratar realidades tão distintas como aquelas vividas nas ex-colônias em comparação com os países mais ricos para estabelecer uma pretensa universalidade que permitiria a representação de todos em uma única escala de classificação.

Em um período subsequente, a investigação científica teve um importante incremento na planificação das políticas sociais, principalmente nos 
Estados Unidos. Escobar (2007, p. 72) aponta que essa crença na ciência era reforçada pela $\mathrm{ONU}$, sendo que, em um discurso em 1948, um alto funcionário afirmou: "[...] que o progresso humano depende do desenvolvimento e aplicação do maior grau possível de investigação científica". Nesse período, ganhou força a ideia de que a pobreza representaria um atrativo para o avanço do comunismo nos países do terceiro mundo (a nova denominação dos subdesenvolvidos não comunistas).

Com o avanço da estatística, os indicadores alçaram voos mais altos, voltando-se também para os estudos demográficos, buscando identificar variáveis de comportamento populacional que eram mensuradas para estabelecer a classificação das populações. De certa forma, tratava-se de estabelecer "boas práticas" populacionais para difundi-las entre os países mais pobres, sobretudo na América Latina, que se tornou alvo do interesse econômico e político. A produção de dados permitiu uma nova forma de intervenção social, baseada em uma racionalidade para além de dados estatísticos, que abarcou o governo das pessoas, permitindo, assim, uma governança por números, desde a forma como vivem, como se comportam, definindo, então, as possibilidades de ação do Estado para inibir comportamentos e condições consideradas inadequadas (POPKEWITZ; LINDBLAD, 2016). Nas décadas seguintes, a aproximação entre a ciência e as políticas sociais foi cada vez maior, a demografia e a estatística se consolidaram como ciências de apoio ao governo como um conhecimento basilar para a condução da economia e da política externa. Essa expertise foi, então, assumida pelas agências de difusão de teorias, como apontava Marini (1994), atualmente denominadas organismos internacionais, que passam a estruturar esse conhecimento em teorias e recomendações, na disseminação de documentos orientadores, legitimados tanto pelo conhecimento científico como pelo seu lugar institucional.

Escobar (2007) observa que a esse discurso orientador das agências internacionais precede uma categorização, uma definição dos "clientes", que são elencados a partir de "anormalidades" a serem corrigidas (subdesenvolvimento, analfabetismo, desnutrição) e, em tempos recentes, na educação (alunos com baixo rendimento, sistemas ineficientes, professores ineficazes). $\bigcirc$ autor ainda aponta que, alijados da realidade local e sujeitos a uma interferência nas condições estruturais e materiais, esses indicadores e essa racionalidade se convertem em poder e controle, sem qualquer capacidade de promover igualdade ou justiça social. 
Marini (1994), que analisou esse dualismo estrutural, aponta para as fragilidades desse modelo teórico de classificação dos países entre desenvolvidos e subdesenvolvidos que, na época e ainda hoje, baseava-se em uma série de indicadores quantitativos (renda per capita, índices de alfabetização e escolaridade, taxas de natalidade e expectativa de vida etc.) capazes tão somente de descrever a realidade. As críticas de Marini, então endereçadas à CEPAL, buscavam demonstrar que nessa metodologia, desenvolvimento e subdesenvolvimento eram, no fundo, a mesma coisa, elementos de uma mesma escala, diferenciados somente por valores numéricos sem qualquer capacidade explicativa e consequentemente de transformação da realidade social.

A crítica feita por Marini ao modelo quantitativo de influência, com o protagonismo das agências internacionais na definição dos "caminhos" a serem seguidos a partir de uma promessa de avanço dos indicadores sociais permanece atual, guardadas as devidas mediações históricas em relação aos avanços científicos e tecnológicos.

sistema de classificação de países, redes e escolas a partir de avaliações quantitativas do desempenho dos alunos alimenta a difusão de uma expertise dos países que se encontram no topo do ranking. Entretanto, como bem analisou Marini (1994), as diferenças entre os primeiros e os últimos colocados é apenas numérica, pouco ou nada desse desempenho se depreende da realidade local e da complexidade social, econômica e cultural de cada país. A legitimação desse processo se assenta justamente nessa classificação mundial e na competição dos indicadores.

Baseados, principalmente, em critérios quantitativos, impostos de fora por especialistas, por órgãos governamentais e pela produção acadêmica, os sistemas de avaliação, classificação e exibição de resultados (rankings) reivindicam o seu reconhecimento atrelado às demandas por justiça social e transparência, estes últimos compreendidos de maneira meritocrática e individualizada (BOLSTANSKI, 2009).

\section{Considerações Finais}

Como uma versão atualizada da Teoria do Capital Humano, a eficiência e a eficácia passam a orientar também a educação básica no Brasil, lançando mão de indicadores quantitativos para indicar desvios e 
inadequações, ou ainda para legitimar ou justificar a formulação ou adoção de uma determinada política.

Nesse sentido, o discurso da excelência e do fracasso, e a discussão em torno de sua qualidade, é sem dúvida um tema-chave de debates e promessas de investimento a cada edição dos Planos Nacionais de Educação e das avaliações nacionais e internacionais.

As mudanças percebidas a partir dessa nova relação estabelecida entre o Estado e a educação no âmbito da NGP se apresentam muito mais na redefinição da natureza da educação, que se desloca da formação humana e cidadã para a excelência competitiva. A persistência das desigualdades educacionais externas e internas indicam a incapacidade do modelo de cumprir a promessa de equiparação estatística com os países de melhor rendimento ou mesmo de avanço dos indicadores nacionais.

A cultura da medição e modelagem que tenta estabelecer valores matemáticos até mesmo para as variáveis mais complexas e subjetivas continua avançando. Uma resposta às críticas ao modelo foi o estabelecimento de um "peso", um valor compensatório para as desigualdades sociais. Esse valor é acrescido ao coeficiente do aluno ou da escola para "compensar" o seu nível socioeconômico ou sua origem social. Com o peso, promove-se um acréscimo matemático aos indicadores. Assim, na sociedade do rendimento, a justiça social se faz pelo avanço do indicador, sem haver necessariamente qualquer intervenção na realidade social.

A produção e a utilização de dados estatísticos na política social não é, certamente, uma invenção da NGP, o que ela traz de "novo" é a capacidade de formulação e fundamentação da política educacional baseada em indicadores que equalizam contextos, culturas e populações. São elaboradas e disseminadas estratégias e caminhos para a excelência que parecem reeditar a Teoria do Capital Humano em uma nova racionalidade. Na sociedade do rendimento e da performance, a excelência não está na ampliação do capital cultural pela escolarização, mas em se moldar ao sujeito idealizado a cada edição das avaliações educacionais comparadas.

Os novos modos de elaboração e orientação da política educacional demostram que, embora enfraquecidas, as matrizes fundantes da igualdade meritocrática, da laicidade e da gratuidade não foram de todo abandonadas. A recomposição dos fundamentos da educação republicana com a 
As matrizes normativas da Nova Gestão Pública e o enfrentamento das desigualdades educacionais

incorporação da eficiência e da eficácia se configura como uma justaposição, uma espécie de organização híbrida, que convive com as persistentes desigualdades sem a perspectiva de uma real equidade dos sistemas educacionais.

\section{Notas}

1 O termo "sistemas" é utilizado para se referir à estrutura de organização da educação no Brasil em concordância com a perspectiva de Saviani (2009).

2 Para um aprofundamento acerca da origem, trajetória e consolidação conceitual da NGP ver: Oliveira, Duarte e Clementino (2017).

3 A Nova Gestão Pública: por um Estado sem burocracia (tradução livre).

4 Uma gestão pública para todas as estações (tradução livre).

5 Educação: estudo setorial (tradução livre).

\section{Referências}

BALL, Stephen John. Education reform. A critical and post-structural approach. Buckingham: Open University Press, 1994.

18 BANCO MUNDIAL. Prioridades y estrategias para la educación. Washington: dc, 1996. Disponivel em: hitp://documentos.bancomundial.org/curated/ es/715681468329483128/pdf/14948010spanish.pdf. Acesso em: 20 fev. 2020. BOLTANSKI, LUC; CHIAPELLO, Ève. O novo espírito do capitalismo. São Paulo: Editora Martins Fontes, 2009.

BURNS, Tracey; SCHULLER, Tom. The Evidence Agenda. OCDE - Centre for Educational Research and Innovation,2007. Disponível em: hitp://www.oecd.org/education/ ceri/47435459.pdf. Acesso em: 11 fev. 2020.

UNESCO/CEPAL. Educación y conocimiento: Eje de la transformación productiva con equidad. Chile, 1992. Disponivel em: hitps://repositorio.cepal.org/bitstream/handle/11362/2130/1/s9250755_es.pdf. Acesso em: 18 fev. 2020.

CUNHA, Luiz Antônio. O projeto reacionário de educação. 2016. Disponível em: hitp:// luizantoniocunha. pro.br/uploads/independente/1-EduReacionaria.pdf. Acesso em: 10 jan. 2020. (E-book).

DASSO JUNIOR, Aragon Érico. "Nova Gestão Pública": a teoria de administração pública do Estado ultraliberal. S/I, 2014. Disponível em: https://document.onl/download/link/ nova-gestao-publica-ngp-a-teoria-de-administracao-publica-do. Acesso em: 20 fev. 2020. 
DÉLOY, Yves. École et citoyenneté-L'individualism républicain de Jules Ferry à Vichy: controverses. Paris: Presse de la FNSP, 1994.

DEROEUT, Jean-Louis; DEROUET, MARIE-CLAUDE. Repenser la justice dans le domaine de l'education et de la formation. Lyon: INRP, 2009.

ESCOBAR, Arturo. La invención del tercer mundo: construcción y deconstrucción del desarrollo. Venezuela: Fundación Editorial, 2007. Disponível em: https://bibliotecapromocion. msp.gob.ec/greenstone/collect/promocin/index/assoc/HASHO 18c.dir/doc.pdf. Acesso em: 12 dez. 2019.

FONSECA, Marília. $\bigcirc$ Banco Mundial como referência para a justiça social no terceiro mundo: evidências do caso brasileiro. Educação e Pesquisa, São Paulo, v. 24, n. 1, p. 37-69, jan. 1998.

LESSARD, Claude. Pesquisa e Políticas Educativas (Verbete). In: van ZANTEN, Agnès (Coord). Dicionário de Educação. Petrópolis: Ed. Vozes, 2011.

LINDBLAD, Sverker; PETTERSON, Daniel; POPKEWITZ, Thomas. (eds.). Education by the Numbers and the Making of Society. The Expertise of International Assessments. New York: Routledge, 2018.

MADAUS, George; AIRASIAN, Peter; KELLAGHAN, Thomas. School effectiveness: a reassessment of the evidence. New York: MacGrow-Hill Book Company, 1980.

MARIANI, Maria Clara. Educação e ciências sociais: o Instituto Nacional de Estudos e Pesquisas Educacionais. In: SCHWARTZMAN, Simon (org.). Universidades e instituições cientificas no Rio de Janeiro. Brasília: CNPq, 1982.

MARINI, Rui Mauro. De lós Orígenes a La Cepal. In: MARINI, Rui Mauro; MILLÁN, Márgara (org.) La teoría social Latinoamericana: UNAM, CELA, 1994. (Tomo 1)

MINTROP, Rick. Gerencialismo neoliberal e profissionalização em escolas dos Estados Unidos. In: OlIVEIRA, Dalila Andrade; CARVALHO, Luís Miguel; LEVASSEUR, Lovis; MIN, Liu; NORMAND, Romuald (org.). Políticas Educacionais e a reestruturação da profissão do educador. Petrópolis: Editora Vozes, 2019

MOSTELLER. Frederick; MOYNIHAN, Daniel. Antecedentes, importância e descobertas do relatório sobre a igualdade de oportunidades educacionais. In: BROOKE, Nigel; SOARES, José Francisco (org.). Pesquisa em eficácia escolar: origem e trajetórias. Belo Horizonte: Editora UFMG, 2008.

MOULIER-BOUTANG, Yann. Le capitalisme cognitif: la nouvelle grande transformation, Paris: Éditions Amsterdam, 2007.

MOULIER-BOUTANG, Yann. of public administration and public policy. New York: Marcel Dekker, 2003. (v. 2). 
As matrizes normativas da Nova Gestão Pública e o enfrentamento das desigualdades educacionais

NÓVOA, António; CARVALHO, Luís Miguel; YANES, Cristina. La comparaison comme politique: le tournant du début du 21 siècle. Nouveaux C@hiers de la Recherche en Education, v. 17, n. 1, p. 121-144, 2014.

ORGANIZAÇÃO Para Cooperação e Desenvolvimento Econômico. New Challenges for Educational Research, Paris, 2003. Disponivel em: https://read.oecd-ilibrary.org/education/new-challenges-for-educational-research_9789264100312-en\#page 1. Acesso em: 14 jan. 2020.

ORGANIZAÇÃO para Cooperação e Desenvolvimento Econômico. Innovation in the Knowledge Economy: Implications for Education and Learning. OECD Publications Service, Paris, 2004. Disponivel em: https://read.oecd-ilibrary.org/education/innovation-in-the-knowledge-economy_9789264105621-en\#page 1. Acesso em: 14 jan. 2020.

ORGANIZAÇÃO para Cooperação e Desenvolvimento Econômico. Evidence in Education: Linking Research and Policy, Paris, 2007. Disponível em: http://www.oecd.org/education/ ceri/evidenceineducationlinkingresearchandpolicy.htm\# 1. Acesso em: 16 jan. 2020.

OLIVEIRA, Dalila Andrade. Educação básica: gestão do trabalho e da pobreza. Petrópolis, Rio de Janeiro: Editora Vozes, 2000.

OlIVEIRA, Dalila Andrade; DUARTE, Alexandre William Barbosa; CLEMENTINO, Ana Maria. A Nova Gestão pública no contexto escolar e os dilemas dos(as) Diretores(as). Revista

20 Brasileira de Política e Administração da Educação, Porto Alegre, v. 33, n. 3, p. 70-726, set./dez. 2017. (Dossiê: A Nova Gestão Pública no contexto escolar: internacionalização de uma agenda para a educação no século XXI).

OLIVEIRA, Dalila Andrade. A profissão docente no contexto da nova gestão pública no Brasil. In: OlIVEIRA, Dalila Andrade; CARVALHO, Luís Miguel; LEVASSEUR, Louis; MIN, Liu; NORMAND, Romuald (org.). Políticas educacionais e a reestruturação da profissão do educador. Petrópolis: Editora Vozes, 2019.

POPKEWITZ, Thomas; LINDBLAD, Sverker. A fundamentação estatística, o governo da educação e a inclusão e exclusão sociais. Educação \& Sociedade, Campinas, v. 37, n. 136, p. 727-754, set. 2016. Disponível em: <http://www.scielo.br/scielo.php?script=sci_art text\&pid=S0 $10173302016000300727 \&$ ng=pt\&nrm=iso>. Acesso em: 23 abr. 2020.

PRESBISCH, Raúl; FURTADO, Celso; PINTO, Aníbal. DESAROLLO Y MODERNIZACIÓN. In: MARINI, Rui Mauro e MILLÁN, Márgara (org.). La teoria social Latinoamericana: de los Orígenes a la CEPAL. México: UNAM, 1994. (Tomo 1).

PROST, Antoine. L'Enseignement est-il démocratisé? Paris, PUF, 1986.

SAUSSEZ, Frédéric; LESSARD, Claude. A educação baseada na prova. De que se trata? Quais são suas implicações? In: FERREIRA, Eliza Bartolozzi; OLIVEIRA, Dalila, Andrade (org.). Crise da escola e políticas educativas. Belo Horizonte: Editora Autêntica, 2009. 
SAVIANI, Dermeval. Sistema de educação: subsídios para a conferência nacional de educação. 2009. Disponível em: http://conae.mec.gov.br/images/stories/pdf/conae_ dermevalsaviani.pdf. Acesso em: 2 nov. 2019.

VAN ZANTEM, Agnès. Política educacional. Dicionário da educação. Petrópolis: Editora Vozes, 2011.

VIGODA, Eran. New public management. In: RABIN, Jack (ed.). Encyclopedia of Public Administration and Public Policy. New York: Marcel Dekker, 2003. (v. 2).

Prof. Dra. Ana Maria Alves Saraiva Universidade Federal de Minas Gerais (Brasil) Faculdade de Educação

Programa de Pós-Graduação em Educação Grupo de Estudos sobre Política Educacional e Trabalho Docente Orcid id: https:/ / orcid.org/0000-0003-1491-6282 E-mail: anasaraiva.ef@gmail.com

Recebido 28 maio 2020

Aceito 13 jul. 2020 